\title{
Efeito de extratos de cascas de café e de arroz na emergência e no crescimento do caruru-de-mancha ${ }^{(1)}$
}

\author{
Julio Cesar Freitas Santos(2), Itamar Ferreira de Souza( ${ }^{(3)}$, Antônio Nazareno Guimarães Mendes ${ }^{(3)}$, \\ Augusto Ramalho de Morais $^{(4)}$, Heráclito Eugenio Oliveira da Conceição ${ }^{(5)}$ \\ e José Tadeu Souza Marinho(6)
}

\begin{abstract}
Resumo - Este trabalho objetivou determinar influências dos extratos aquosos de cascas de café e de arroz na emergência e no crescimento inicial do caruru-de-mancha (Amaranthus viridis L.). O delineamento experimental foi em blocos casualizados, com quatro repetições, em esquema fatorial $(2 \times 2 \times 5)$, sendo dois tipos de casca, em dois solos (lavoura de café e terra de barranco) e cinco concentrações dos extratos $(0,5,10,15$ e 20\%). Extratos aquosos de cascas de café e de arroz, nas concentrações entre 10 e $20 \%$, proporcionaram, respectivamente, maior estímulo e inibição na emergência. $\mathrm{O}$ extrato de casca de café proporcionou maior crescimento inicial e massa da matéria seca do caruru-de-mancha, enquanto a velocidade e a porcentagem de emergência foram mais inibidas por extrato de casca de arroz.
\end{abstract}

Termos para indexação: Coffea arabica, Oryza sativa, Amaranthus viridis, alelopatia, resíduos.

\section{Effect of extracts of coffee and rice husks upon emergence and growth of the slender amaranth}

\begin{abstract}
This work aimed to determine the effects of aqueous extracts of coffee and rice husks on emergence and initial growth of slender amaranth (Amaranthus viridis L.). The experimental design was a randomized block with four replications in a $(2 \times 2 \times 5)$ factorial scheme, being two types of husks, in two soils (coffee crop and steep bank), and five extracts concentrations (0, 5, 10, 15 and 20\%). Coffee and rice husks aqueous extracts between 10 and $20 \%$ concentrations provided respectively greater seed emergence stimulation and inhibition. Coffee husk extract caused greater initial growth and dry matter weight of slender amaranth, while emergence velocity and percentage were more inhibited by rice husk extract.
\end{abstract}

Index terms: Coffea arabica, Oryza sativa, Amaranthus viridis, allelopathy, residues.

(1) Aceito para publicação em 11 de outubro de 2001.

Extraído da dissertação de mestrado apresentada pelo primeiro autor à Universidade Federal de Lavras (Ufla), Lavras, MG.

(2) Embrapa-Centro de Pesquisa Agroflorestal de Rondônia, Caixa Postal 406, CEP 78900-970 Porto Velho, RO. E-mail: julio@cpafro.embrapa.br

(3) Ufla, Dep. de Agricultura, Caixa Postal 37, CEP 37200-000 Lavras, MG. E-mail: itamarfs@ufla.br, nazareno@ufla.br

(4)Ufla, Dep. de Ciências Exatas. E-mail: armorais@ufla.br

(5) Embrapa-Centro de Pesquisa Agroflorestal da Amazônia Oriental, Caixa Postal 48, CEP 66095-100 Belém, PA. E-mail: heraclit@cpatu.embrapa.br

(6) Embrapa-Centro de Pesquisa Agroflorestal do Acre, Caixa Postal 392, CEP 69908-970 Rio Branco, AC. E-mail: tadeu@cpafac.embrapa.br

\section{Introdução}

Tradicionalmente, para determinação do potencial alelopático de uma planta, tem-se recorrido inicialmente à técnica dos extratos aquosos e orgânicos. Realizada em laboratório e casa de vegetação, esta técnica é considerada a mais simples e usual, fundamentada na capacidade de melhor isolar o efeito alelopático de outras interferências (Gomide, 1993).

Exemplo comum de determinação do potencial alelopático de uma planta sobre outra é o estudo dos efeitos dos extratos de resíduos de plantas infestantes sobre sementes ou plântulas de espécies cultivadas, geralmente de ciclo anual, devido à interferência das plantas infestantes na produção e rentabilidade dessas culturas. A alelopatia pode ocorrer entre espécies cultivadas, de espécies cultivadas 
sobre plantas infestantes e vice-versa, e entre as próprias plantas infestantes (Rice, 1984).

A técnica da extração dos aleloquímicos consiste em mergulhar o material fresco ou seco em um solvente por um determinado período de tempo e, após filtração, obtém-se o extrato. Esses extratos podem ser feitos com toda planta ou órgãos, inteiros ou triturados. O solvente mais utilizado nas extrações é a água destilada (Fischer \& Kummer, 1993) seguido por solventes orgânicos de vários graus de polaridade.

O emprego de extrato aquoso em testes alelopáticos tem como objetivo procurar simular o que acontece na natureza. Muitas substâncias químicas ou aleloquímicos, que se encontram em plantas vivas ou resíduos, geralmente são lixiviadas em quantidades significativas pela chuva e orvalho para o solo (Medeiros, 1989).

$\mathrm{Na}$ lavoura cafeeira, por exemplo, é freqüente o uso de resíduos vegetais como restos de cultivos intercalares, massa vegetal da própria flora infestante e coberturas mortas de cascas de café e de arroz (Souza et al., 1985), tendo os dois últimos comprovados efeitos alelopáticos sobre algumas espécies infestantes (Medeiros, 1989; Almeida, 1991a; Araújo et al., 1993; Kito et al., 1995).

O caruru-de-mancha (Amaranthus viridis L.) é uma planta infestante que se encontra presente na maioria das lavouras cafeeiras do Brasil (Souza et al., 1985; Matiello, 1991), possui a capacidade de mobilizar grandes quantidades de nutrientes (Gallo et al., 1963) e ainda apresenta efeito alelopático inibitório sobre cultura (Marques, 1992).

O objetivo deste trabalho foi determinar a influência dos extratos aquosos de cascas de café e de arroz sobre a emergência e o crescimento inicial do caruru-de-mancha.

\section{Material e Métodos}

O experimento foi realizado no período de abril a junho de 1998, em casa de vegetação do Departamento de Agricultura da Universidade Federal de Lavras (Ufla), Lavras, MG.

O delineamento experimental adotado foi em blocos casualizados com quatro repetições. Vinte tratamentos foram dispostos num esquema fatorial $(2 \times 2 \times 5)$, com os fatores principais correspondendo a dois tipos de casca (café e arroz), dois solos (lavoura de café e terra de barranco) e cinco concentrações $(0,5,10,15$ e $20 \%)$ dos extratos aquosos. Cada parcela foi representada por um vaso de plástico com capacidade de um litro.
$\mathrm{Na}$ preparação dos extratos aquosos, os resíduos de casca de café e casca de arroz foram imersos em água destilada durante seis horas na proporção de $400 \mathrm{~g} / 2.000 \mathrm{~mL}$, resultando na solução inicial ou solução estoque a $20 \%$ de concentração. Após a filtragem desta solução estoque, foram extraídas alíquotas que, juntamente com as respectivas proporções de água destilada, possibilitaram a obtenção das demais soluções de menores concentrações: $5,10 \mathrm{e}$ $15 \%$. A solução a $0 \%$, constituída apenas de água destilada, foi a testemunha.

Foi medido o pH dos extratos de cascas de café e de arroz nas concentrações de $5,10,15$ e $20 \%$, cujas médias gerais foram $5,48 \pm 0,34$ e $6,41 \pm 0,17$ respectivamente, com a testemunha apresentando $\mathrm{pH} 7,23$.

Dois tipos de solos foram utilizados como substratos, sendo um coletado da camada arável $(0-20 \mathrm{~cm})$ de uma lavoura de café em produção e o outro de um perfil de barranco de terra num local afastado da citada lavoura. As análises química e granulométrica de uma amostra composta de cada um destes solos foram realizadas no Departamento de Ciência do Solo da Ufla, Lavras, MG (Tabela 1). Estes substratos foram peneirados e acondicionados nos vasos, num total de 40 para cada tipo de solo.

Foram semeadas vinte sementes de caruru-de-mancha por vaso, e em seguida, aplicados $50 \mathrm{~mL}$ de cada solução (concentração do extrato) na superfície de cada vaso.

A irrigação foi realizada em intervalos de dois dias, aplicando-se, em média, $150 \mathrm{~mL}$ de água destilada na bandeja suporte de cada vaso. Constituiu-se, assim, uma irrigação por capilaridade, objetivando evitar a percolação total do extrato. As plantas infestantes foram arrancadas manualmente.

Durante o experimento foram realizadas leituras diárias de temperatura e umidade relativa do ar, por nove semanas, cujas médias gerais foram $17,29^{\circ} \mathrm{C} \pm 2,43^{\circ} \mathrm{C}$ e $67,00 \% \pm 3,64 \%$, respectivamente.

No $37^{\circ}$ dia após a semeadura, foi efetuado o desbaste das plantas, com o corte rente ao solo, deixando apenas cinco plantas por vaso.

O índice de velocidade de emergência (IVE) foi obtido por meio de contagem diária do número de plantas de caruru, emergidas até $043^{\circ}$ dia da semeadura, e de cálculo segundo o critério de Maguire (1962).

Quando ocorreu a estabilização da emergência do caruru ( $43^{\circ}$ dia após a semeadura), a porcentagem de emergência foi calculada pela relação do número de plântulas obtidas com o número de sementes semeadas por vaso.

A altura da planta foi medida com régua nas cinco plantas de cada vaso, a partir do $37^{\circ}$ dia após a semeadura, em intervalos de sete dias, totalizando cinco avaliações até a data de encerramento do experimento, no $65^{\circ}$ dia após a semeadura. 
Nos mesmos períodos de avaliações da altura foi procedida a contagem do número de folhas, de cada planta. A partir dos dados do número de folhas, foi calculada a taxa de emissão foliar, que correspondeu à diferença em número de folhas entre duas datas de avaliações consecutivas, dividida pelo período, em dias, entre tais avaliações.

Através de observações visuais, foram descritos os sintomas de danos ocorridos nas plantas de caruru e calculada a porcentagem de plantas afetadas em relação à testemunha.

Após 28 dias do desbaste (65 dias após a semeadura), foi efetuado o corte rente ao solo da parte aérea das plantas, separando-se as folhas dos caules, ramos, pecíolos e inflorescências. Em seguida, os vasos foram imersos em água para lavagem do substrato e retirada do sistema radicular. Após, o material foi acondicionado separadamente, em sacos de papel Kraft, e colocado para secar por sete dias, em estufa elétrica com circulação forçada de ar a $40^{\circ} \mathrm{C}$. A massa da matéria seca foi obtida pela pesagem separada da parte aérea e do sistema radicular em balança eletrônica digital, sendo o resultado expresso em g/100 plantas.

A área foliar foi calculada, no final do experimento, pela aplicação do método do disco foliar, adaptado por Benincasa (1988). Foi utilizado o alicate de extração de disco foliar com diâmetro padrão de $1 \mathrm{~cm}$, para coleta de quatro amostras, contendo cada uma cinco discos foliares com áreas e massas da matéria seca conhecidas, possibilitando, conforme a obtenção das respectivas massas da matéria seca da folha, a execução do cálculo de sua área foliar

A análise de variância foi realizada conforme adaptação de Pimentel-Gomes (1990). Os dados referentes à porcentagem de plantas germinadas foram transformados para arc sen $(\mathrm{x} / 100)^{0,5}$, e os referentes à contagem de folhas, convertidos para $(\mathrm{x}+1)^{0,5}$. Quando houve efeito significativo das concentrações e de suas interações, estas foram estudadas pela análise de regressão.

\section{Resultados e Discussão}

O índice de velocidade e a porcentagem de emergência do caruru-de-mancha não foram influenciados pelo tipo de solo utilizado.

Os teores de argila nos solos de lavoura de café e terra de barranco foram praticamente iguais, $60 \%$ e $66 \%$, respectivamente (Tabela 1). Isto pode ter con- tribuído para a falta de significância nas interações alelopáticas, pois em relação à casca de café, a cafeína é o alcalóide que deve estar presente em seu extrato, podendo ser fortemente retido pelas argilas (Lailach et al., 1968 citados por Mazzafera et al., 1996), em proporções semelhantes, o que acarretou resultados sem muita diferença. Os valores de $\mathrm{pH}$ foram semelhantes e o teor de matéria orgânica do solo de barranco foi $10 \%$ maior do que o do solo de lavoura de café.

O valor da saturação de base do solo de lavoura de café foi $30 \%$ mais elevado do que o do solo de barranco.

A casca de arroz possui maior predominância de substâncias fenólicas, cujos compostos, citados em Almeida (1988), apresentam grande solubilidade em água, menor capacidade de degradação e maior poder de acumulação no solo. $O$ fato de o solo, em relação à casca de arroz, também não ter influenciado nas interações, pode ser atribuído aos teores quase semelhantes de argila e de matéria orgânica nos dois solos.

Os efeitos dos extratos aquosos das cascas apresentaram comportamentos diferenciados sobre o índice de velocidade de emergência do caruru, tendo a casca de café proporcionado um aumento linear e a casca de arroz um comportamento quadrático (Figura 1).

A velocidade de emergência das plantas aumentou à medida que a concentração do extrato de casca de café aumentou, ou seja, houve um acréscimo médio de 0,03508 no IVE para cada unidade de aumento na concentração do extrato. $\mathrm{O}$ extrato da casca de arroz promoveu estímulo deste índice até a concentração de $10 \%$, e a partir daí, ocorreu inibição.

A relação entre a porcentagem de emergência do caruru e os extratos das cascas de arroz foi linear e inversa, isto é, houve um decréscimo de $0,40 \%$ na emergência do caruru para cada incremento de $1 \%$ na concentração do extrato (Figura 1). A casca de café resultou em comportamento quadrático, com uma emergência mínima de $40,7 \%$, ocorrendo na concentração de 7,7\% do extrato e aumentando com maiores concentrações, tendo um efeito estimulador.

No entanto, Almeida (1991b) observou que a aplicação de extrato aquoso da casca de café causou

Tabela 1. Análise química e granulométrica de amostras $(0-20 \mathrm{~cm})$ de solos de lavoura de café (A) e em perfil de barranco de terra $(\mathrm{B})$.

\begin{tabular}{|c|c|c|c|c|c|c|c|c|c|c|c|c|c|c|c|c|}
\hline Solo & $\begin{array}{c}\mathrm{pH} \\
\text { água } 1: 2,5\end{array}$ & $\begin{array}{c}\mathrm{MO} \\
(\mathrm{dg} / \mathrm{kg})\end{array}$ & & $\begin{array}{c}\mathrm{K} \\
\left.\mathrm{Im}^{3}\right)\end{array}$ & $\begin{array}{c}\mathrm{Ca} \\
---\end{array}$ & $\mathrm{Mg}$ & Al & $\begin{array}{c}\mathrm{H}+\mathrm{Al} \\
\left(\mathrm{cmol}_{\mathrm{c}} / \mathrm{dm}^{3}\right)\end{array}$ & SB & $\mathrm{t}$ & $\begin{array}{r}\mathrm{T} \\
---\end{array}$ & $\mathrm{m}$ & $\mathrm{V}$ & $\begin{array}{l}\text { Argila } \\
-(\%)--\end{array}$ & Areia & Silte \\
\hline $\mathrm{A}$ & 5,8 & 24,8 & 10 & 78 & 2,3 & 1,1 & 0,0 & 2,6 & 3,6 & 3,6 & 6,2 & 0,0 & 58,1 & 60 & 27 & 13 \\
\hline B & 5,8 & 27,4 & 1 & 44 & 0,8 & 0,2 & 0,4 & 5,0 & 1,1 & 1,5 & 6,1 & 26,7 & 18,0 & 66 & 15 & 19 \\
\hline
\end{tabular}


inibição da germinação de várias espécies de plantas silvestres, inclusive o caruru-gigante (Amaranthus retroflexus L.). Fetene \& Habtemariam (1995) constataram que extratos de folhas e frutos de café inibiram a germinação da alface, e atribuíram esse efeito à presença da cafeína, alcalóide, que ocorre em maior quantidade no fruto do café (Mazzafera et al., 1991).

Resultados divergentes de efeitos entre os extratos de casca de café e casca de arroz sobre o caruru podem ser resultantes da concentração de seus
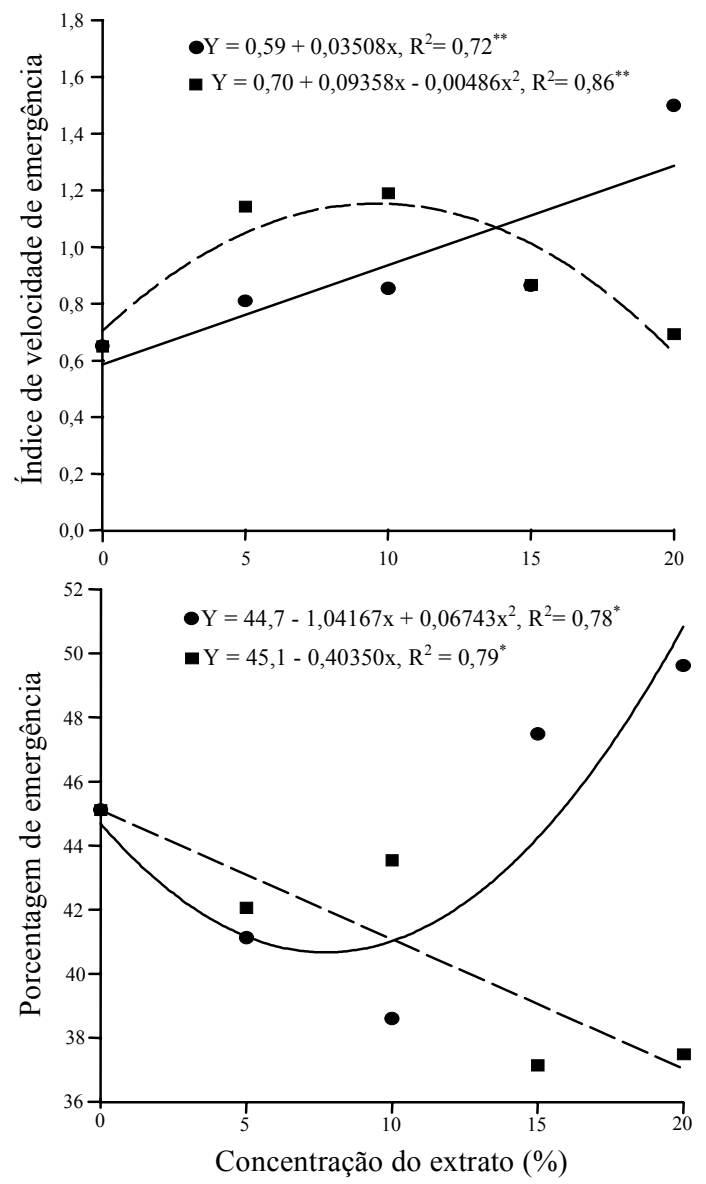

Figura 1. Efeito dos extratos aquosos de cascas de café (O) e de arroz (ם) e de suas concentrações, no índice de velocidade (IVE) e na porcentagem (\%) de emergência do caruru-de-mancha, no $43^{\circ}$ dia após a semeadura em vaso $(\mathrm{p}<0,05)$. aleloquímicos no meio. Conforme McCalla \& Haskins (1964), citados por Marques (1992), substâncias consideradas inibitórias à germinação possuem efeito estimulante sobre esse processo em baixas concentrações, com os inibidores parecendo agir sobre a atividade enzimática e outras atividades fisiológicas da planta. Isto, provavelmente, deve ocorrer com a casca de arroz, pois conforme Tamak et al. (1994), à medida que aumentava a concentração de extrato aquoso de resíduos de arroz, aumentava a inibição na germinação de determinadas espécies.

Segundo Lorenzi (1983), citado por Gomide (1993), a ação alelopática de extratos aquosos não tem sido só inibitória, pois tem ocorrido também casos de ação estimuladora de uma planta sobre a germinação ou crescimento de outra.

Quanto à altura das plantas, em todos os períodos de avaliações, o extrato da casca de café causou aumento quadrático, enquanto o de casca de arroz mostrou-se com resultado constante, ou seja, o coeficiente angular da reta (b) foi zero (Figura 2). O extrato de casca de café, ao longo do período de avaliação, promoveu maior incremento da altura da planta de caruru, principalmente a partir da concentração $10 \%$, quando comparado ao efeito da casca de arroz. Este estímulo ao crescimento do caruru pode estar relacionado em parte, ao efeito provocado pela substância alelopática cafeína. $\mathrm{O} \mathrm{N}$ contido em sua composição pode ter favorecido esse estímulo.

Kitou \& Yoshida (1997), estudando efeitos de resíduos de café no crescimento de diversas plantas, verificaram aumento significativo da taxa de crescimento das plantas de feijão, soja e alface, e decréscimo da taxa nas plantas de trigo, milho e algumas espécies infestantes. Esses autores constataram que os resíduos de café provocaram estímulo maior no crescimento de plantas latifoliadas ou dicotiledôneas, enquanto nas monocotiledôneas registrou-se efeito inverso.

A casca de café proporcionou um aumento linear no número de folhas emitidas, e a casca de arroz, por sua vez, apresentou resultados constantes e com valores inferiores ao da casca de café (Figura 3).

A casca de café causou, no geral, efeito linear crescente na produção de matéria seca do caruru em solo de lavoura e aumento quadrático em solo de barranco (negativo nas concentrações até 10\%) (Figura 4). A casca de arroz proporcionou resultado 

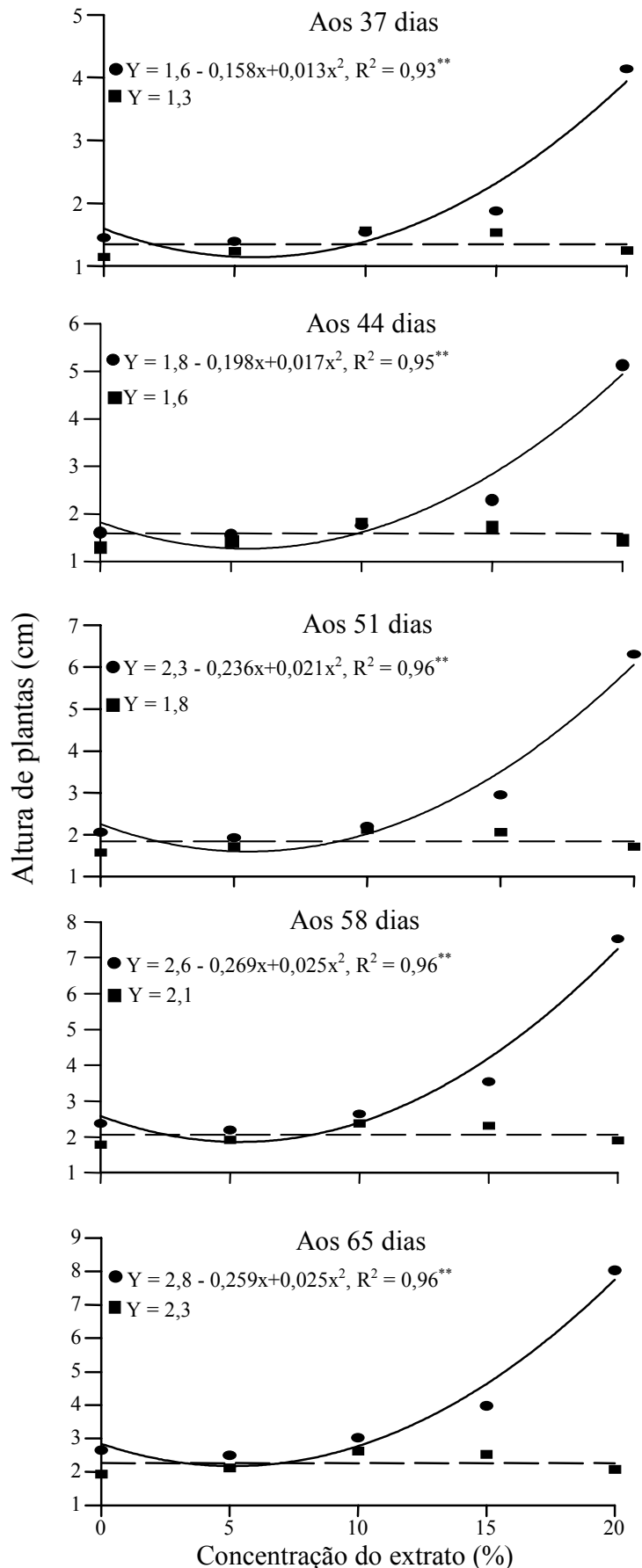

Figura 2. Efeito dos extratos aquosos de cascas de café (O) e de arroz (ם) e de suas concentrações, na altura de plantas do caruru-de-mancha, aos 37, 44, 51, 58 e 65 dias após a semeadura em vaso $(p<0,05)$

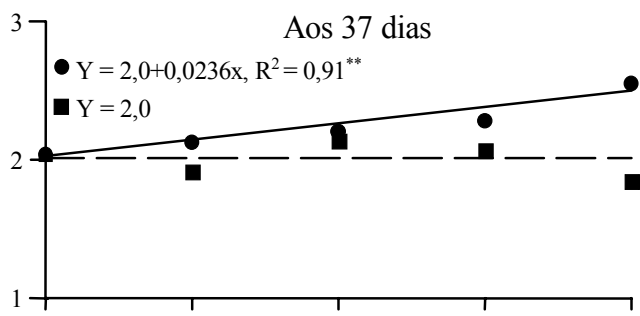

Aos 44 dias
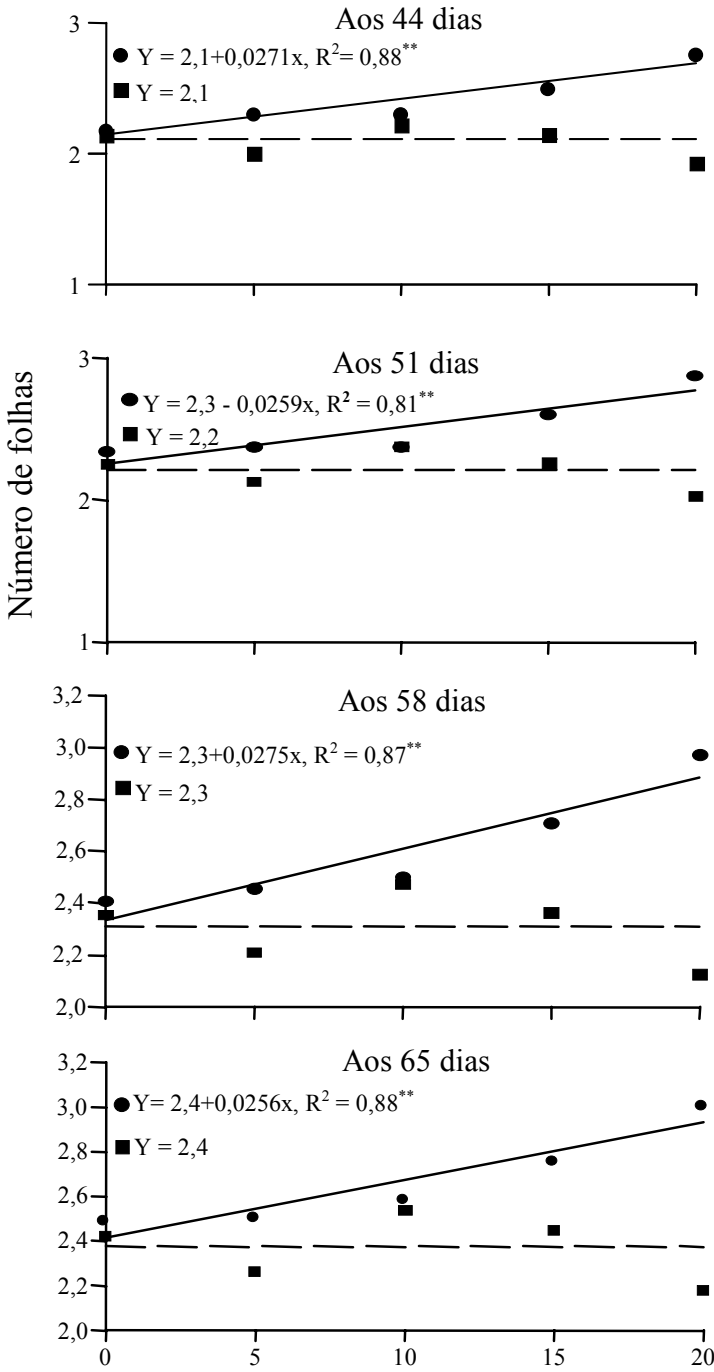

Concentração do extrato (\%)

Figura 3. Efeito dos extratos aquosos de cascas de café (O) e de arroz ( $\mathbf{\square})$ e de suas concentrações, no número de folhas emitidas pelo caruru-de-mancha, aos 37, 44, 51, 58 e 65 dias após a semeadura em vaso $(\mathrm{p}<0,05)$.

Pesq. agropec. bras., Brasília, v. 37, n. 6, p. 783-790, jun. 2002 
Lavoura
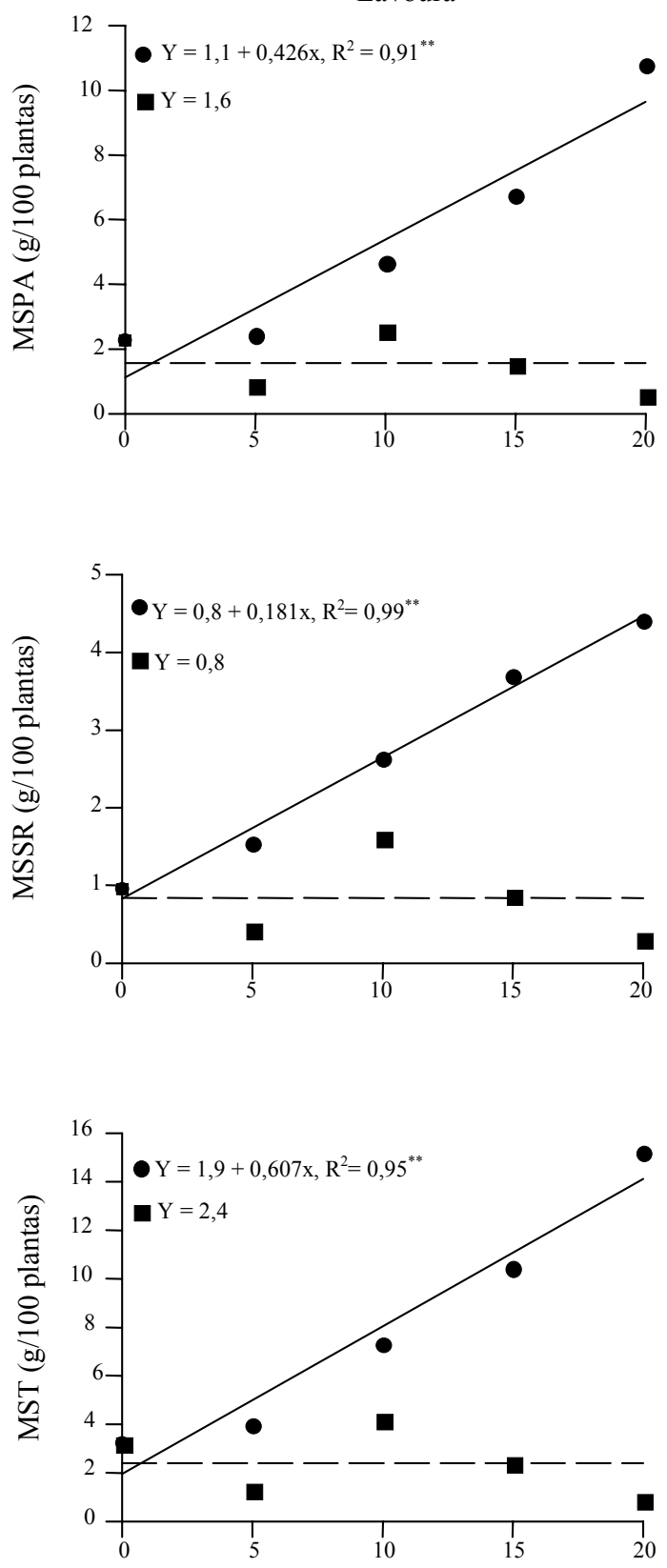

Barranco
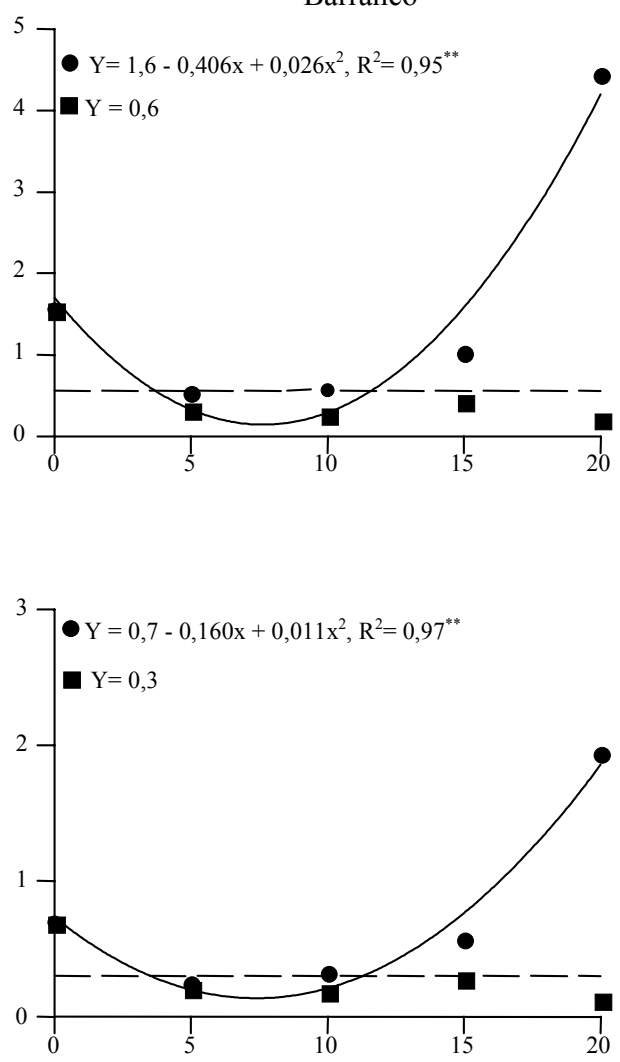

Concentração do extrato $(\%)$

Figura 4. Efeito dos extratos aquosos de cascas de café (O) e de arroz ( $\boldsymbol{\square})$ e de suas concentrações, em solo de lavoura de café e barranco, na massa da matéria seca da parte aérea (MSPA), do sistema radicular (MSSR) e total (MST) do caruru-de-mancha aos 65 dias após a semeadura em vaso, com as médias gerais de 2,28, 1,13 e 3,41 g/100 plantas, respectivamente. 
linear constante, independentemente de concentração e solo, tendo menor influência na massa da matéria seca do que a casca de café (exceção nas concentrações de 5 a $10 \%$ em solo de barranco).

Resíduos de cereais de espécies monocotiledôneas podem apresentar ou não, maior ou menor influência alelopática sobre plantas dicotiledôneas de folhas largas (Almeida \& Rodrigues, 1985). Exemplo comum é a susceptibilidade de Amaranthus sob influência alelopática de extratos aquosos de resíduos de trigo (Rambakudzibga, 1991; Li et al. 1996; Narwal\&Sarmah, 1996).

No geral, observou-se que a massa da matéria seca da parte aérea foi superior à das raízes, indicando maior sensibilidade das raízes à influência alelopática de extratos (Figura 4). Maior sensibilidade das raízes comparada à da parte aérea das plantas, mesmo sob concentrações muito baixas, foram citadas em Miró et al. (1998). Almeida \& Rodrigues (1985) também observaram que extratos aquosos da parte aérea de trigo, triticale, aveia e centeio, induziram maior redução no comprimento da raiz do amendoim-bravo, em comparação ao comprimento de suas folhas.

O efeito do extrato de casca de café na área foliar foi linear em solo de lavoura de café e quadrático em solo de barranco (Figura 5). Por sua vez, a casca de arroz apresentou resultados lineares constantes. Além dos índices de área foliar da casca de café serem superiores aos da casca de arroz, os valores em solo de lavoura foram maiores do que em solo de barranco.

Quanto aos sintomas de danos apresentado pelo caruru, houve maior porcentagem em solo de barranco. Curvamento da planta na metade superior do caule, queda de folhas primárias, clorose e necrose das pontas das folhas novas foram causados pela casca de café de maneira uniforme. O número de plantas afetadas em relação à testemunha sob extrato de casca de café a $15 \%$ e $20 \%$ correspondeu em $15 \%$ e $35 \%$ em solo de barranco e $10 \%$ e $20 \%$ em solo de lavoura de café, respectivamente. A casca de arroz com extrato a $20 \%$ de concentração provocou sintomas de clorose foliar, seguida de necrose. O número de plantas afetadas por esse extrato em relação à testemunha foi de $40 \%$ em solo de barranco, e $20 \%$ em solo de lavoura.

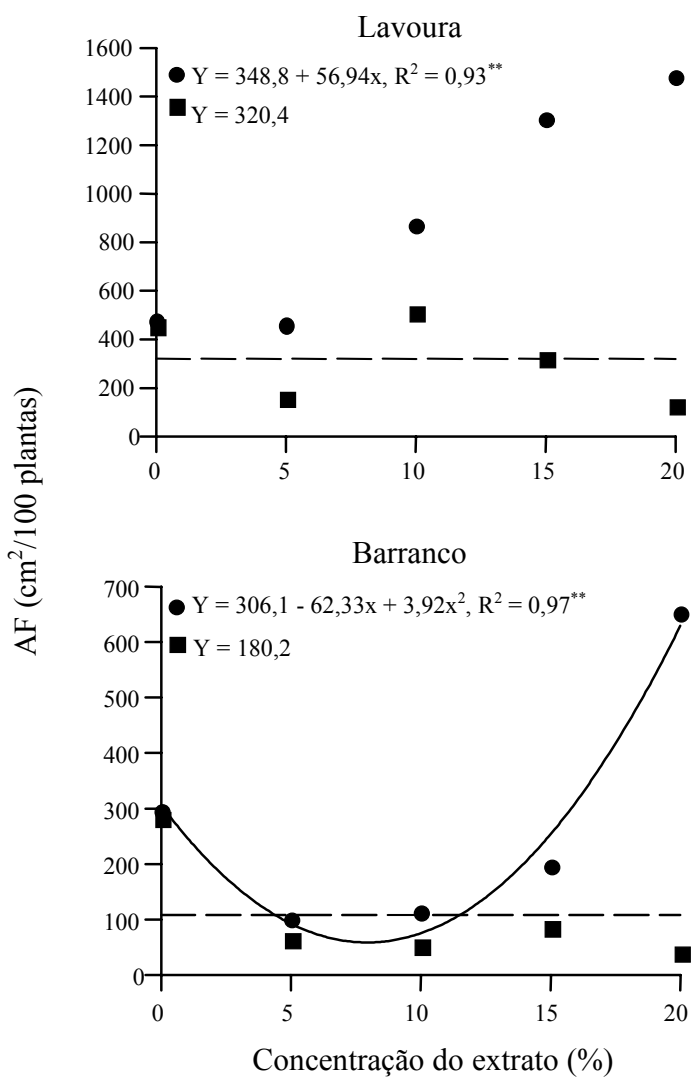

Figura 5. Efeito dos extratos aquosos de cascas de café (O) e de arroz ( $\square$ ) e de suas concentrações, em solo de lavoura de café e barranco, na área foliar (AF) do caruru-de-mancha aos 65 dias após a semeadura em vaso, com média geral de $404,57 \mathrm{~cm}^{2} / 100$ plantas.

\section{Conclusões}

1. Extrato aquoso de casca de arroz propicia maior inibição na velocidade e porcentagem de emergência do caruru-de-mancha do que extrato de casca de café.

2. Extrato aquoso de casca de café exerce maior estímulo no crescimento da planta e na produção de matéria seca do caruru-de-mancha do que extrato de casca de arroz.

\section{Referências}

ALMEIDA, F. S. de. A alelopatia e as plantas. Londrina: Instituto Agronômico do Paraná, 1988. 60 p. 
ALMEIDA, F. S. de. Controle de plantas daninhas em plantio direto. Londrina: Instituto Agronômico do Paraná, 1991a. 34 p.

ALMEIDA, F. S. de. Efeitos alelopáticos de resíduos vegetais. Pesquisa Agropecuária Brasileira, Brasília, v. 26, n. 2, p. 221-236, fev. 1991b.

ALMEIDA, F. S.; RODRIGUES, B. N. Plantio direto. In: FUNDAÇÃO INSTITUTO AGRONÔMICO DO PARANÁ (Londrina, PR). Guia de herbicidas: contribuição para o uso adequado em plantio direto e convencional. Londrina, 1985. p. 341-399.

ARAÚJO, R. da C.; SOUZA, R. J. de; SILVA, A. M.; ALVARENGA, M. A. R. Efeitos da cobertura morta do solo sobre a cultura do alho (Allium sativum). Ciência e Prática, Lavras, v. 17, n. 3, p. 228-233, jul./set. 1993.

BENINCASA, M. M. P. Análise de crescimento de plantas: noções básicas. Jaboticabal: Unesp, 1988. 41 p.

FETENE, M.; HABTEMARIAM, S. Investigations on allelopathic properties of coffee (Coffea arabica L.) leaves, pulp and tree-conopy soil. Sinet, Adis Abeba, v. 18, n. 1, p. 51-65, 1995.

FISCHER, A. G.; KUMMER, P. M. Process for decaffeinating raw coffee. United States Patent US 5208056, 1993. 4 p.

GALLO, R.; MORAES, F. R.P. de; LOTT, W. L.; INFORZATO, R. Absorção de nutrientes pelas ervas daninhas e sua competição com o cafeeiro. Campinas: Instituto Agronômico, 1963. 13 p. (Boletim, 104).

GOMIDE, M. B. Potencialidades alelopáticas dos restos culturais de dois cultivares de cana-de-açúcar (Saccharum sp.), no controle de algumas plantas daninhas. 1993. 96 f. Tese (Doutorado em Fitotecnia) - Escola Superior de Agricultura Luiz de Queiroz, Piracicaba.

KITO, M.; OKUNO, S.; HAMADA, Y. Study on the agricultural utilization of coffee residue: utilization of coffee residue for weed control. Kyoto: Asic, 1995. p. 821-828. (Colloque, 16).

KITOU, M.; YOSHIDA, S. Effect of coffee residue on the growth of several crops species. Journal of Weed Science and Technology, Honshu, v. 4, n. 1, p. 25-30, 1997.

LI, S. L.; YOU, Z. G.; LI, S. R.; ZHANG, L. Allelopathy of wheat extracts to the growth of two weeds. Chinese Journal of Biological Control, Beijing, v. 12, n. 4, p. 169170, 1996.

MAGUIRE, J. D. Speed of germination aid in selection and evaluation for seedling emergence and vigor. Crop Science, Madison, v. 2, n. 1, p. 176-177, Mar./Apr. 1962.
MARQUES, M. A. Potencial alelopático de resíduos de caruru (Amaranthus viridis) incorporado em três tipos de solos, sobre a germinação e crescimento inicial do algodoeiro (Gossypium hirsutum). 1992. $125 \mathrm{f}$. Dissertação (Mestrado em Solos e Nutrição de Plantas) Universidade Federal de Lavras, Lavras.

MATIELlO, J. B. O café: do cultivo ao consumo. São Paulo: Globo, 1991. 320 p.

MAZZAFERA, P.; CROZIER, A.; MAGALHÃES, A. C. Caffeine metabolism in Coffea arabica and others species of coffee. Phytochemistry, Oxford, v. 30, n. 12, p. 39133916, 1991.

MAZZAFERA, P.; YAMAOKA-YANO, D. M.; VITÓRIA, A. P. Para que serve a cafeína em plantas? Revista Brasileira de Fisiologia Vegetal, Brasília, v. 8, n. 1, p. 67-74, 1996.

MEDEIROS, A. R.M. de. Determinação de potencialidades alelopáticas em agroecossistemas. 1989. $92 \mathrm{f}$. Tese (Doutorado em Fitotecnia) - Escola Superior de Agricultura Luiz de Queiroz, Piracicaba.

MIRÓ, C. P.; FERREIRA, A. G.; AQUILA, M. E. A. Alelopatia de frutos de erva-mate (Ilex paraguariensis) no desenvolvimento do milho. Pesquisa Agropecuária Brasileira, Brasília, v. 33, n. 8, p. 1261-1270, ago. 1998.

NARWAL, S. S.; SARMAH, M. K. Effect of wheat residues and forage crops on the germination and growth of weeds. Allelopathy Journal, Haryana, v. 3, n. 2, p. 229240, 1996.

PIMENTEL-GOMES, F. Curso de estatística experimental. 13. ed. Piracicaba: Nobel, 1990. 468 p.

RAMBAKUDZIBGA, A. M. Allelopathic effects of aqueous wheat (Triticium aestivum L.) straw extracts on the germination of eight arable weeds commonly found in Zimbabwe. Zimbabwe Journal of Agricultural Research, Causeway, v. 29, n. 1, p. 77-79, 1991.

RICE, E. L. Allelopathy. 2. ed. Orlando: Academic, 1984. $422 \mathrm{p}$.

SOUZA, I. F. de; MElles, C. do C. de A.; GUIMARÃES, P. T. G. Plantas daninhas e seu controle. Informe Agropecuário, Belo Horizonte, v. 11, n. 126, p. 59-65. 1985.

TAMAK, J. C.; NARWAL, S. S.; SINGH, L.; SINGH, I. Effect of aqueous extracts of rice stubbles and straw + stubbles on the germination and seedling growth of wheat, oat, berseem and lentil. Crop Research, Hisar, v. 8, n. 1, p. 180-185, 1994. 